\title{
Fetal Entrapment in the Myometrium Caused by Ectopic Implantation Post Myomectomy
}

Fetal entrapment in myometrial dehiscence after myomectomy has been rarely reported. A 38-yearold woman, gravida 4, parity 2, with suspected amniotic or adhesion band was referred to our hospital at 234/7 weeks. She had undergone open myomectomy and cesarean delivery twice. Ultrasonography revealed two separate compartments divided by a septum-like structure with a small orifice. Magnetic resonance imaging (MRI) finding suggested an ectopic implantation on the endometric and myometrial dehiscence. At 25 weeks, the thoracic cage and umbilical cord escaped through the orifice. Emergent cesarean delivery and subtotal hysterectomy were performed for the placental increta at the myometrial dehiscent site. In fetal entrapment in myometrial dehiscence, MRI is valuable for the assessment of the fetus and spatial arrangement in the uterine cavity.

Key Words: Dehiscence, Entrapment, Fetal, Myomectomy, Uterus

\section{Introduction}

The risk of uterine rupture or dehiscence in pregnant women with prior myomectomy is relatively well recognized. According to the literature and meta-analysis, the risk of uterine rupture after laparoscopic myomectomy is $0.75 \%$, similar to that of laparotomic myomectomy. ${ }^{1}$ A recent single-center study in Korea also showed that in 523 pregnancies, uterine rupture after laparoscopic myomectomy occurred in 0.6\% (3 cases); miscarriage, in $13 \%$; and preterm delivery, in $10.4 \% .{ }^{2}$ Uterine rupture after a previous uterine surgery can manifest as a frank rupture or dehiscence. Unlike frank rupture, uterine dehiscence is incidentally observed at the time of cesarean delivery. ${ }^{3}$ However, fetal entrapment in myometrial dehiscence after myomectomy is rarely reported. Here, we present the diagnosis and management of a stuck fetus in the myometrium, which was initially suspected as an intrauterine adhesion band, in a woman with a history of myomectomy.

\section{Case}

E-mail:ohsymd.oh@samsung.com, ohsymd@skku.edu

Copyright@ 2020 by The Korean Society of Perinatology

This is an Open Access article distributed under the terms of the Creative Commons Attribution Non-Commercial License (http://creativecommons.org/ license/by-nc/4.0/), which permits unrestricted non-commercial use, distribution, and reproduction in any medium, provided that the original work is properly cited. 
filled with amniotic fluid. The deepest pocket in the upper and lower compartments was 1.1 and $14.6 \mathrm{~cm}$ deep, respectively. The diameter and band thickness of the orifice between the two compartments were 3.3 and $0.7 \mathrm{~cm}$, respectively, and the left shoulder of the fetus protruded through the band orifice but could move up and down while showing moderate edema. The patient was hospitalized for lower abdominal discomfort and continuous fetal surveillance.

Fetal magnetic resonance imaging (MRI) performed the following day after admission indicated that the pregnancy was based on an ectopic implantation probably through the endometric and myometrial dehiscence, and the main amniotic sac was herniated into the original uterine cavity as the fetus grew (Fig. 2). We assumed an extrauterine adhesion due to abnormal ectopic implant- ation. The amniotic sac was herniated through the myometrial dehiscence into the original uterine cavity.

Finally, at 25 weeks, not only the fetal arm but also part of the thoracic cage and umbilical cord escaped through the orifice. The fetal heartbeat showed recurrent variable deceleration followed by prolonged deceleration of approximately 60 beats per minute (bpm) for 15 minutes. Therefore, an emergent cesarean delivery was performed via a vertical incision in the upper compartment of the uterus. A male neonate weighing $790 \mathrm{~g}$ was delivered, with an Apgar score of 1 at 1 minute and 5 at 5 minutes. We could not take a cord blood sample because of umbilical cord collapse. As the placental increta was complicated and the patient did not want further pregnancy, a subtotal hysterectomy was performed. She remained hemodynamically stable with a
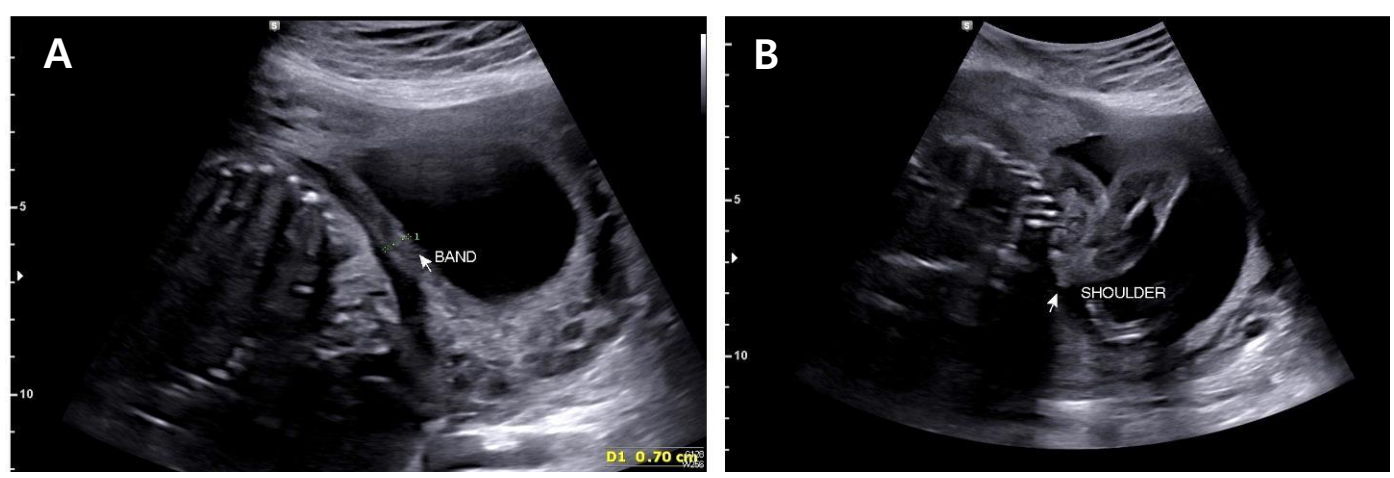

Fig. 1. Ultrasonographic images. (A) A horizontal band-like structure in the upper third of the uterus. (B) The fetal left shoulder protruding into the herniated amniotic sac through the small orifice. Accordingly, the herniated left upper arm (arrows) appears edematous because of the entrapment.
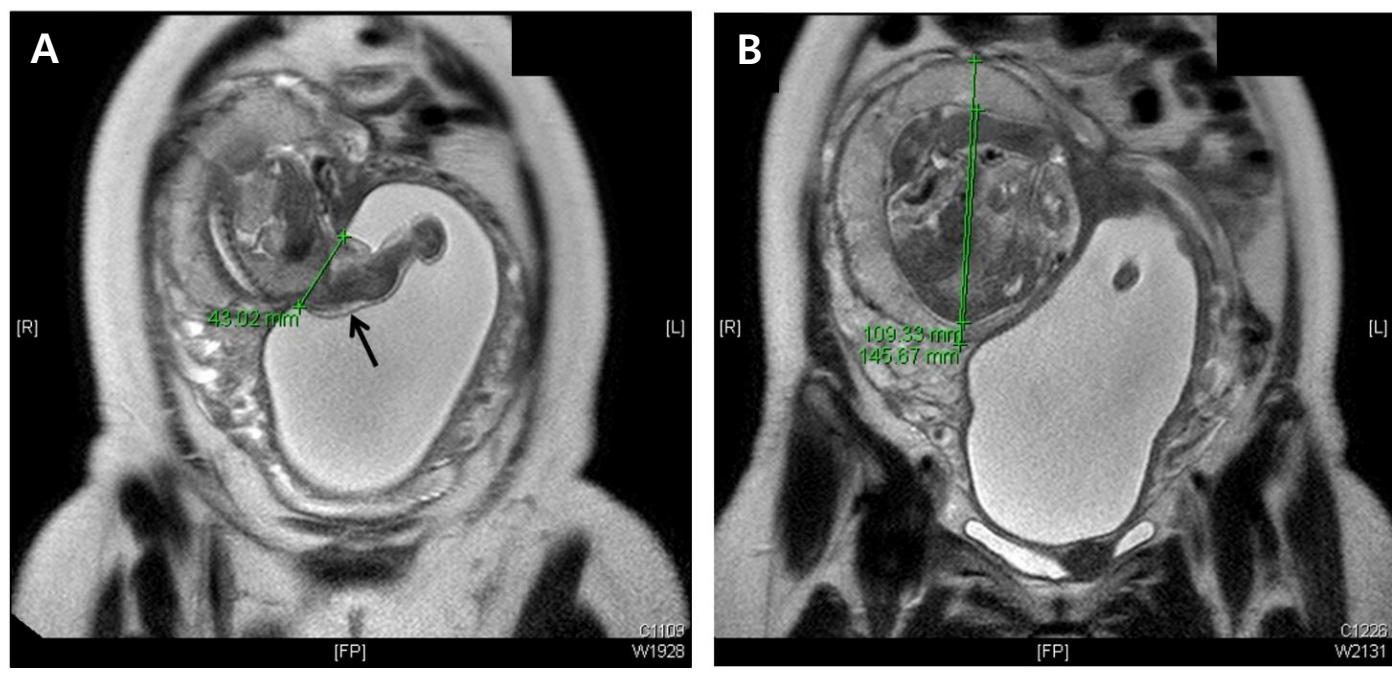

Fig. 2. Fetal T2-weighted magnetic resonance images. (A) The main amniotic sac is herniated into the original intrauterine cavity. The left shoulder (arrow) is edematous because it passes out through the small myometrial dehiscence. (B) The fetus is entrapped within the myometrial dehiscence, resulting from an ectopic implantation. 
postoperative hemoglobin level of $10.4 \mathrm{~g} / \mathrm{dL}$ and was discharged on postoperative day 4. Unfortunately, the baby died 15 days after birth because of severe pulmonary hypoplasia and proven late-onset neonatal sepsis caused by Staphylococcus aureus.

According to the pathological examination of the uterus, the right upper mid-portion of the uterine cavity demonstrated a myometrial dehiscence rather than an intrauterine adhesion band, forming the second uterine cavity connected to the original one by a narrow opening (Fig. 3). The placental disc adhered and invaded the myometrium surrounding the dehiscent site. The placental tissue showed increased syncytial knots and large fetal vessels with thrombi, suggesting maternal underperfusion and fetal thrombotic vasculopathy; however, neither acute chorioamnionitis nor funisitis was observed.

\section{Discussion}

We report an unusual case of fetal entrapment secondary to an ectopic implantation in a patient with a previous myomectomy. Most ectopic implantation (95\%) occur in the ampulla, infundibular, and isthmic segments of the fallopian tube. Fewer than $5 \%$ of ectopic implantation occur in the interstitial segment of the fallopian tube, cervix, and anterior lower uterine segment of the cesarean delivery scar, ovary, or peritoneal cavity. ${ }^{4}$ Herein, we report a case of implantation in the myometrial dehiscence site that was confirmed by gross pathological examination.

Through a search on PubMed (English language; through April 2020; search terms: "uterus," “dehiscence," "synechia," "fetal," and "entrapment," both individually and with several combinations), we identified four references on intrauterine fetal entrapment. In 2003, Deering et al. ${ }^{5}$ reported a case with intrauterine head entrapment of the second twin by uterine synechia that progressed to fetal distress with a cesarean delivery. ${ }^{5}$ In 2016, Bouet et al. ${ }^{6}$ published a case with fetal legs in a large herniated amniotic sac through a 2.5-cm uterine dehiscence in a patient who had five previous cesarean deliveries. ${ }^{6}$ In 2017, fetal leg entrapment was reported in a patient with uterine diverticulum secondary to a previous uterine instrumentation complicated by compartment syndrome and rupture of the diverticular portion. ${ }^{7}$ In the three previous cases, the patients were previously indicated for uterine surgery such as uterine curettage or cesarean delivery. One case without surgical intervention was fetal entrapment secondary to the compartmentalization due to a
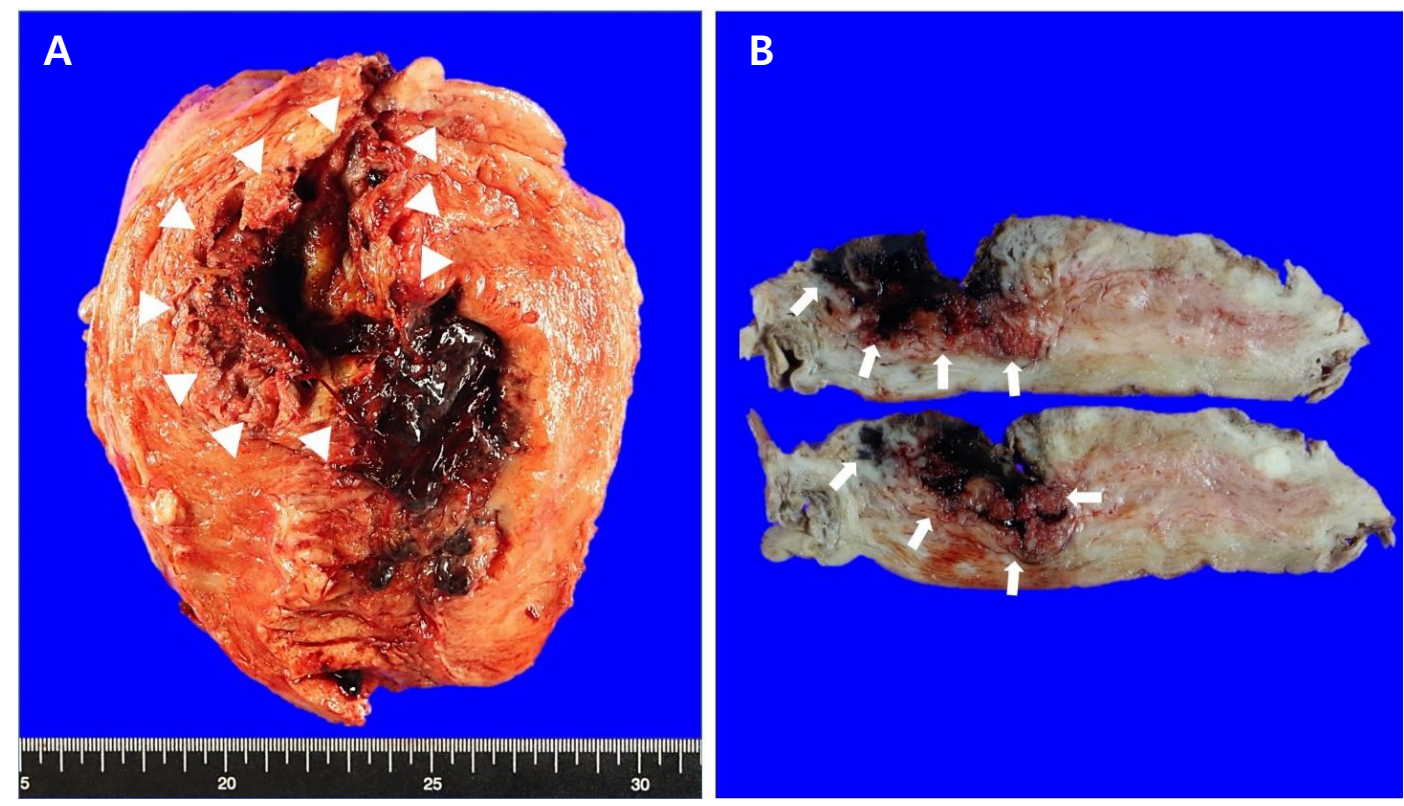

Fig. 3. Gross findings of the uterus. (A) (Coronal section, mid-portion) The white arrowheads indicate the second uterine cavity created by the myometrial dehiscence. The original endometrial cavity at the left lower portion is covered by hemorrhagic decidua but shows no adhesion. (B) (Cross section) Placental increta confirmed on the basis of the placental remnants adhering to and invading the myometrium at the uterine dehiscent site (arrows). 
submucosal myoma. ${ }^{8}$ To our best knowledge, this is a rare case of fetal entrapment with ectopic implantation in myometrial dehiscence.

A herniated amniotic sac, which is a fetal membrane bulging into the abdominal cavity, is an unusual manifestation of uterine rupture or dehiscence during pregnancy. According to a study by lemura et al. ${ }^{9}$ who summarized 24 cases of herniated amniotic sac, 21 patients had a history of cesarean delivery, uterine curettage, and myomectomy, ${ }^{9}$ whereas 2 patients had no prior intrauterine intervention and the remaining patient had only a history of amniocentesis. Mishina et al. ${ }^{10}$ also reported a case without a history of intrauterine intervention except amniocentesis after that amniotic sac was prolapsed through the small uterine wall defect. ${ }^{10}$ In these cases, the fetus was in the intrauterine cavity and herniated amniotic sac was located in the abdominal cavity. Our case is the reverse of the above-mentioned cases in terms of herniation, that is, ectopic implantation in the myometrial dehiscence caused fetal entrapment and herniation of the amniotic sac into the original intrauterine cavity. As the amniotic fluid volume in the compartment where the fetus was scant, severe pulmonary hypoplasia of the neonate seemed inevitable.

The fetal entrapment associated with oligohydramnios can lead to similar fetal and neonatal consequences of early onset preterm premature rupture of membranes. Usually, severe oligohydramnios in the second trimester cause fetal lung hypoplasia, frequently resulting in neonatal death. ${ }^{11}$ In general, the prevalence of lung hypoplasia in cases of early onset oligohydramnios (occurring at $<24$ weeks) is known to be $11.1-25 \%$. ${ }^{12-14}$ Meanwhile, the optimal timing of delivery with mid-trimester oligohydramnios has not been clearly determined. In ongoing pregnancies of fetal entrapment complicated with oligohydramnios, the risks and potential sequelae of cord compression, preterm birth, and neonatal abnormalities need to be discussed. Serial ultrasonography for the assessment of amniotic fluid volume and continuous fetal heartrate monitoring for abrupt events related to entrapment may be necessary. Also, according to the American College of Obstetrics and Gynecologists guideline for periviable births, antenatal corticosteroids can be considered for infants born between 230/7 and 256/7 weeks of gestation. ${ }^{15}$ In our case, we decided on continuous fetal heartrate monitoring at 234/7 weeks of gestation and acute cord compression hap- pened through the orifice of the cavity of entrapment during the hospital stay.

In general, pregnancies in women with previous myomectomy are considered as high-risk pregnancies and the risk of uterine rupture is the major concern. ${ }^{16}$ According to a systemic review of the literature based on 23 studies, the overall incidence of uterine rupture was $0.6 \%{ }^{17}$ Unlike with uterine rupture during labor in women with a previous cesarean scar, uterine rupture after prior myomectomy occurred mainly before 36 weeks and before labor. ${ }^{17}$ According to a recent study in Japan analyzing 153 cases of uterine rupture after myomectomy, the mean gestational age at uterine rupture was $30-32$ weeks. ${ }^{18}$ Considering the potential impact of uterine rupture on mothers and their fetuses, it was noted that physicians should provide adequate counseling including the risk of ruptures during a subsequent pregnancy when myomectomy is to be performed. ${ }^{3,19}$ Also, thorough investigation of the uterine wall and location of the gestational sac during the first trimester of pregnancy may be helpful in women who have previously undergone uterine intervention.

In conclusion, we report a rare case of fetal entrapment in myometrial dehiscence in a patient who had a prior myomectomy. In a previously reported case of uterine synechia or amniotic band syndrome, fetoscopic surgery released the fetal entrapment. ${ }^{20}$ However, we did not consider fetoscopic intervention because of the myometrial dehiscence. Once this condition is diagnosed, close surveillance of the fetal heart rate is vital. The use of MRI is valuable for understanding the spatial arrangement in the uterine cavity and precise assessment of the fetus and placental implantation.

\section{Financial Disclosure}

The authors did not report any potential conflicts of interest.

\section{References}

1) Claeys J, Hellendoorn I, Hamerlynck T, Bosteels J, Weyers S. The risk of uterine rupture after myomectomy: a systematic review of the literature and meta-analysis. Gynecol Surg 2014;11:197-206.

2) Koo YJ, Lee JK, Lee YK, Kwak DW, Lee IH, Lim KT, et al. Pregnancy outcomes and risk factors for uterine rupture after laparoscopic myomec- 
tomy: a single-center experience and literature review. J Minim Invasive Gynecol 2015;22:1022-8.

3) Kim HS, Oh SY, Choi SJ, Park HS, Cho GJ, Chung JH, et al. Uterine rupture in pregnancies following myomectomy: a multicenter case series. Obstet Gynecol Sci 2016;59:454-62.

4) Chukus A, Tirada N, Restrepo R, Reddy NI. Uncommon implantation sites of ectopic pregnancy: thinking beyond the complex adnexal mass. RadioGraphics 2015;35:946-59.

5) Deering SH, Heller J, Winkel C, Landy HJ. Intrauterine head entrapment of a second twin by a uterine synechia. Obstet Gynecol 2003;102:693-5.

6) Bouet $P E$, Herondelle C. Uterine rupture with protruded legs in a large amniocele. N Engl J Med 2016;375:e51.

7) Chandrasekaran N, Yudin MH, Berger H. Uterine diverticulum with fetal leg entrapment: a case report. J Obstet Gynaecol Can 2017;39:894-6.

8) Dinglas C, Kunzier N, Sanchi J, Chavez M, Vintzileos A. Ultrasoundguided manipulation of fetal entrapment by a large uterine fibroid. Am J Obstet Gynecol 2015;213:870.e1-2.

9) lemura A, Kondoh E, Kawasaki K, Fujita K, Ueda A, Mogami H, et al. Expectant management of a herniated amniotic sac presenting as silent uterine rupture: a case report and literature review. J Matern Fetal Neonatal Med 2015;28:106-12.

10) Mishina M, Hasegawa J, Ichizuka K, Oba T, Sekizawa A, Okai T. Defect in the uterine wall with prolapse of amniotic sac into it at 32 weeks' gestation in a primigravida woman without any previous uterine surgery. J Obstet Gynaecol Res 2014;40:840-2.

11) Shipp TD, Bromley B, Pauker S, Frigoletto FD Jr, Benacerraf BR. Outcome of singleton pregnancies with severe oligohydramnios in the second and third trimesters. Ultrasound Obstet Gynecol 1996;7:108-13.

12) Everest NJ, Jacobs SE, Davis PG, Begg L, Rogerson S. Outcomes following prolonged preterm premature rupture of the membranes. Arch Dis Child Fetal Neonatal Ed 2008;93:F207-11.
13) Xiao ZH, André $P$, Lacaze-Masmonteil $T$, Audibert $F$, Zupan $V$, Dehan $M$. Outcome of premature infants delivered after prolonged premature rupture of membranes before 25 weeks of gestation. Eur J Obstet Gynecol Reprod Biol 2000;90:67-71.

14) Falk SJ, Campbell LJ, Lee-Parritz A, Cohen AP, Ecker J, Wilkins-Haug L, et al. Expectant management in spontaneous preterm premature rupture of membranes between 14 and 24 weeks' gestation. J Perinatol 2004; 24:611-6

15) American College of Obstetricians and Gynecologists; Society for Maternal-Fetal Medicine. Obstetric Care consensus No. 6: periviable birth. Obstet Gynecol 2017;130:e187-99.

16) American Association of Birth Centers; Association of Women's Health, Obstetric and Neonatal Nurses; American College of Obstetricians and Gynecologists; Society for Maternal-Fetal Medicine, Kilpatrick SJ, et al. Obstetric Care Consensus \#9: Levels of Maternal Care: (Replaces Obstetric Care Consensus Number 2, February 2015). Am J Obstet Gynecol 2019; 221:B19-30.

17) Gambacorti-Passerini Z, Gimovsky AC, Locatelli A, Berghella V. Trial of labor after myomectomy and uterine rupture: a systematic review. Acta Obstet Gynecol Scand 2016;95:724-34.

18) Makino S, Takeda S, Kondoh E, Kawai K, Takeda J, Matsubara S, et al. National survey of uterine rupture in Japan: Annual report of Perinatology Committee, Japan Society of Obstetrics and Gynecology, 2018. J Obstet Gynaecol Res 2019;45:763-5.

19) Marret $H$, Fritel $X$, Ouldamer $L$, Bendifallah $S$, Brun JL, De Jesus I, et al. Therapeutic management of uterine fibroid tumors: updated French guidelines. Eur J Obstet Gynecol Reprod Biol 2012;165:156-64.

20) Keswani SG, Johnson MP, Adzick NS, Hori S, Howell LJ, Wilson RD, et al. In utero limb salvage: fetoscopic release of amniotic bands for threatened limb amputation. J Pediatr Surg 2003;38:848-51. 